\title{
Impact of lockdown on air quality in India during COVID-19 pandemic
}

\author{
Ramesh P. Singh ${ }^{1}$ (D) A Akshansha Chauhan ${ }^{2}$ \\ Received: 26 May 2020 / Accepted: 23 June 2020 / Published online: 7 July 2020 \\ (C) Springer Nature B.V. 2020
}

\begin{abstract}
First time in India, total lockdown was announced on 22 March 2020 to stop the spread of COVID-19 and the lockdown was extended for 21 days on 24 March 2020 in the first phase. During the total lockdown, most of the sources for poor air quality were stopped in India. In this paper, we present an analysis of air quality (particulate matter- $\mathrm{PM}_{2.5}$, Air Quality Index, and tropospheric $\mathrm{NO}_{2}$ ) over India using ground and satellite observations. A pronounced decline in $\mathrm{PM}_{2.5}$ and AQI (Air Quality Index) is observed over Delhi, Mumbai, Hyderabad, Kolkata, and Chennai and also a declining trend was observed in tropospheric $\mathrm{NO}_{2}$ concentration during the lockdown period in 2020 compared with the same period in the year 2019. During the total lockdown period, the air quality has improved significantly which provides an important information to the cities' administration to develop rules and regulations on how they can improve air quality.
\end{abstract}

Keywords COVID-19 $\cdot$ Air quality $\cdot$ Lockdown $\cdot$ US Embassies $\cdot$ India

\section{Introduction}

COVID-19 is considered as one of the major disasters, which has impacted the whole world. Wuhan city, capital of Hubei province of China, faced the first outbreak of this COVID-19 during December 2019 and all nations of the world are affected by COVID-19 in a gradual manner (Raibhandari et al. 2020; Wang et al. 2020a, b). After China, most South Asian Countries like Japan, South Korea, and others are affected by the cross-border travels. The return of Chinese workers spread COVID-19 in Italy. The Government of India issued an advisory for travelers from China during early January and also started screening the travelers from China (https://www. mygov.in/covid-19/?cbps=1). In response to the global COVID-19 pandemic, the Indian Prime Minister announced Janata (people's) curfew on 22 March 2020 from 7 am until 9 pm (https://economictimes.indiatimes.com/news/politicsand-nation/after-janata-curfew-india-gets-ready-for-long-

Ramesh P. Singh

rsingh@chapman.edu

1 School of Life and Environmental Sciences, Schmid College of Science and Technology, Chapman University, Orange, CA 92866, USA

2 Formerly with Department of Environmental Science, Sharda University, Greater Noida 201310, India haul/articleshow/74765039.cms). Soon after, the Government of India announced a complete nationwide lockdown, from 24 March 2020 for 21 days (14 April 2020) (https://www.bbc. com/news/world-asia-india-52024239), all the domestic and international flights, trains, and vehicular transport except for non-essential purposes were stopped and banned. Such lockdown was unique in India; total lockdown was not seen in any other countries. This sudden decision impacted poor people and migrant workers in major cities, Delhi, and Mumbai. These migrant workers were daily wages and without any job, it was difficult for them to survive. Migrant workers in Delhi and Mumbai even started walking to their hometown from far distant places since there was no means of transportation available.

In general, the Northern parts of India are subjected to poor air quality and atmospheric pollution, mainly due to emissions from vehicles, industry, brick kilns, coal-based power plants, and crop residue burning (Singh et al. 2004, Prasad et al. 2006, Venkataraman et al. 2018). For instance, New Delhi, capital of India, suffers with sustained poor air quality where pollution levels are higher compared with Beijing (Zheng et al. 2017). The air quality and atmospheric pollution in China has improved in recent years, whereas in India, the poor air quality has persistently increased over the last several decades associated with growing anthropogenic activities (Chauhan and Singh 2017, Sarkar et al. 2018, 2019). In recent past, the Delhi Government conducted experiments of permitting odd 
or even licensed vehicles on the road to curb the pollution level (like Beijing). However, such experiments have generally not helped or improved the air quality of Delhi (Chandra et al. 2018).

Recently, Wang et al. (2020a, b) carried out an analysis of $\mathrm{PM}_{2.5}$ data in a number of Chinese cities, Beijing, Shanghai, Guangzhou, and Wuhan during COVID-19, and found a pronounced reduction in air pollution attributed to the reduction of emissions in transportation and industrial sectors. Muhammad et al. (2020) found 20-30\% reduction in emission of $\mathrm{NO}_{2}$ in China, Spain, France, Italy, and the USA due to lockdown. Chauhan and Singh (2020) observed a decline in $\mathrm{PM}_{2.5}$ in major cities of the world.

During complete lockdown in India, roads were deserted without any vehicle except the emergency vehicles. The month of April every year is the peak time of winter crop harvesting (wheat) and planting of vegetables in India, so the Government relaxed the movement of farmers from lockdown in the second phase during 15 April-3 May 2020. The Government of India has further extended lockdown in some parts in a relaxed manner; now they have opened vehicular transport, domestic flights, and few trains; as a result the air quality is getting poor. Also, farmers at many places have started burning crop residue, and long-term transport of dusts during the pre-monsoon season are also being observed, which affects the air quality of Delhi and major cities located in the Indo-Gangetic Plains (IGP). Recently, Sharma et al. (2020) considered the Central Pollution Control Board dataset and studied the impact of lockdown on air quality for the period 15 March to 14 April 2020.

The aim of this paper is to study the impact of a complete lockdown in India on air quality $\left(\mathrm{PM}_{2.5}\right.$, AQI, and $\mathrm{NO}_{2}$ ) during COVID-19 by comparing air quality parameters during March 2019 and 2020. Our results show a pronounced decline in $\mathrm{PM}_{2.5}$, AQI, and $\mathrm{NO}_{2}$ over major cities where US embassies are located during the complete lockdown period (22-30 March 2020). We have considered air quality parameters $\left(\mathrm{PM}_{2.5}\right.$ and AQI) from the US Embassy located in five Indian cities, and $\mathrm{NO}_{2}$ is considered from the satellite data. In India, wheat crop is harvested during April and May and that affects the air quality due to emission of various pollutants.

\section{Data used}

For our study, we have considered major cities, Delhi, Kolkata, Mumbai, Chennai, and Hyderabad, where US embassies are located. The details of US embassies are given in Table 1.

\section{$\mathrm{PM}_{2.5}$ data}

The US embassies are located in five major metropolitan cities in India, New Delhi (30 million), Mumbai (25 million), Hyderabad (12.91 million), Kolkata (15.6 million), and Chennai (10.96 million) (Fig. 1); in the bracket, the populations are given as per the latest census. We have studied two primary air quality parameters $\left(\mathrm{PM}_{2.5}\right.$ particulate matter with a particle size of 2.5-micron diameter and Air Quality IndexAQI) which are monitored by each respective US embassies at five locations. Data are taken from the US Environmental Protection Agency (EPA) through AirNow portal (https:// www.airnow.gov/index.cfm?action=airnow.global summary). The EPA claims to provide better quality of data.

\section{$\mathrm{NO}_{2}$ data}

We have considered tropospheric $\mathrm{NO}_{2}$, one of the major pollutants which is highly dependent on the local sources because of its short residential time in the atmosphere. We have considered tropospheric $\mathrm{NO}_{2}$ data from the Ozone Monitoring Instrument (OMI). OMI is part of the NASA A-train satellite missions, which measures the concentration of various trace gases in the atmosphere. We have used OMI version 3 data which has a 1-day temporal and $0.25^{\circ} \times 0.25^{\circ}$ spatial resolutions. The details of the data are discussed by Krotkov et al. (2019). The data are downloaded through NASA Giovanni portal (https://giovanni.gsfc.nasa.gov/). We have selected a $1^{\circ} \times 1^{\circ}$ square box (Table 1 ) over the five US embassies in India to study the temporal variation of tropospheric $\mathrm{NO}_{2}$.

\section{HYSPLIT model}

We have carried out the trajectory analysis over Delhi, Mumbai, Hyderabad, Chennai, and Kolkata using the NOAA HYSPLIT model (https://ready.arl.noaa.gov/ HYSPLIT.php) to study the sources of air mass reaching at five locations. The back trajectories were analyzed for $100 \mathrm{~h}$ to track the air mass reaching at the measuring site; after every $6 \mathrm{~h}$, these trajectories are overlapped on the world map. The details of the HYSPLIT model are discussed by Stein et al. (2015).

\section{Results and discussion}

Figure 1 shows the impact of complete lockdown in India, average $\mathrm{PM}_{2.5}$ concentrations during March 2020, and after lockdown period (22-31 March 2020) along with the average $\mathrm{PM}_{2.5}$ concentration during March 2019. The average concentration of $\mathrm{PM}_{2.5}$ before lockdown was higher in comparison 
Table 1 Location of the US embassies in India along with the coordinates of Boxes over major cities

\begin{tabular}{lccc}
\hline Station Name & Latitude & Longitude & Box coordinates for $\mathrm{NO}_{2}$ data from OMI satellite \\
\hline Delhi & 28.59 & 77.18 & W-76.68, S-28.07, E-77.68, N-29.07 \\
Kolkata & 22.54 & 88.35 & W-87.86, S-22.08, E-88.86, N-23.08 \\
Mumbai & 19.06 & 72.86 & W-72.42, S-18.55, E-73.42, N-19.55 \\
Hyderabad & 17.44 & 78.47 & W-77.78, S-17.01, E-78.78, N-18.01 \\
Chennai & 13.05 & 80.25 & W-79.76, S-12.56, E-80.76, N-13.56 \\
\hline
\end{tabular}

with the concentration after lockdown. The $\mathrm{PM}_{2.5}$ concentration in Kolkata is reduced by $34.52 \%$, and $27.57 \%$ in Delhi, capital of India. In general, $\mathrm{PM}_{2.5}$ is much higher throughout the year in the northern parts of India especially in the IndoGangetic Plains (IGP). During pre-monsoon (March-June), winter season (December-January), and crop residue burning seasons (mid-October to mid-November), $\mathrm{PM}_{2.5}$ varies in a range of $400-800 \mu \mathrm{gm} / \mathrm{m}^{3}$ (Sarkar et al. 2018, 2019). In Mumbai, Chennai, and Hyderabad, $\mathrm{PM}_{2.5}$ was reduced by $19.25 \%, 5.40 \%$, and $3.99 \%$, respectively. The dominance of westerly wind from arid and semi arid region and lower temperature along the Indo-Gangetic plains in the month of March, the average concentration of $\mathrm{PM}_{2.5}$ remains higher in comparison to other cities. The proximity of Mumbai and Chennai to the sea, the air mass mostly reaches from the sea surface during March and the $\mathrm{PM}_{2.5}$, is lower in comparison with Delhi and Kolkata. Similar changes are also observed in the Air Quality Index (AQI) which is a function of $\mathrm{PM}_{2.5}$ and other emissions. The improvement in air quality is clearly observed mainly due to lockdown during 22-31 March 2020. This lockdown is now extended until 17 May 2020 with little relaxation in some of the localities in cities where no case of COVID-19 was found. In India, complete lockdown was observed in a phased manner. We have considered data only for the phase 1 to avoid influence of crop harvesting, long range transport of dusts, and crop residue burning on the air quality in the month of April and later months. We have carried out an analysis of air mass trajectory for four different time periods. In Fig. 2, we have shown air mass back trajectories at five locations of US embassies during 10-21 March and 22-31 March for the years 2019 and 2020. The back trajectories provide details about the sources of air mass reaching to five measurement locations. We have observed that Delhi is mostly influenced by western and
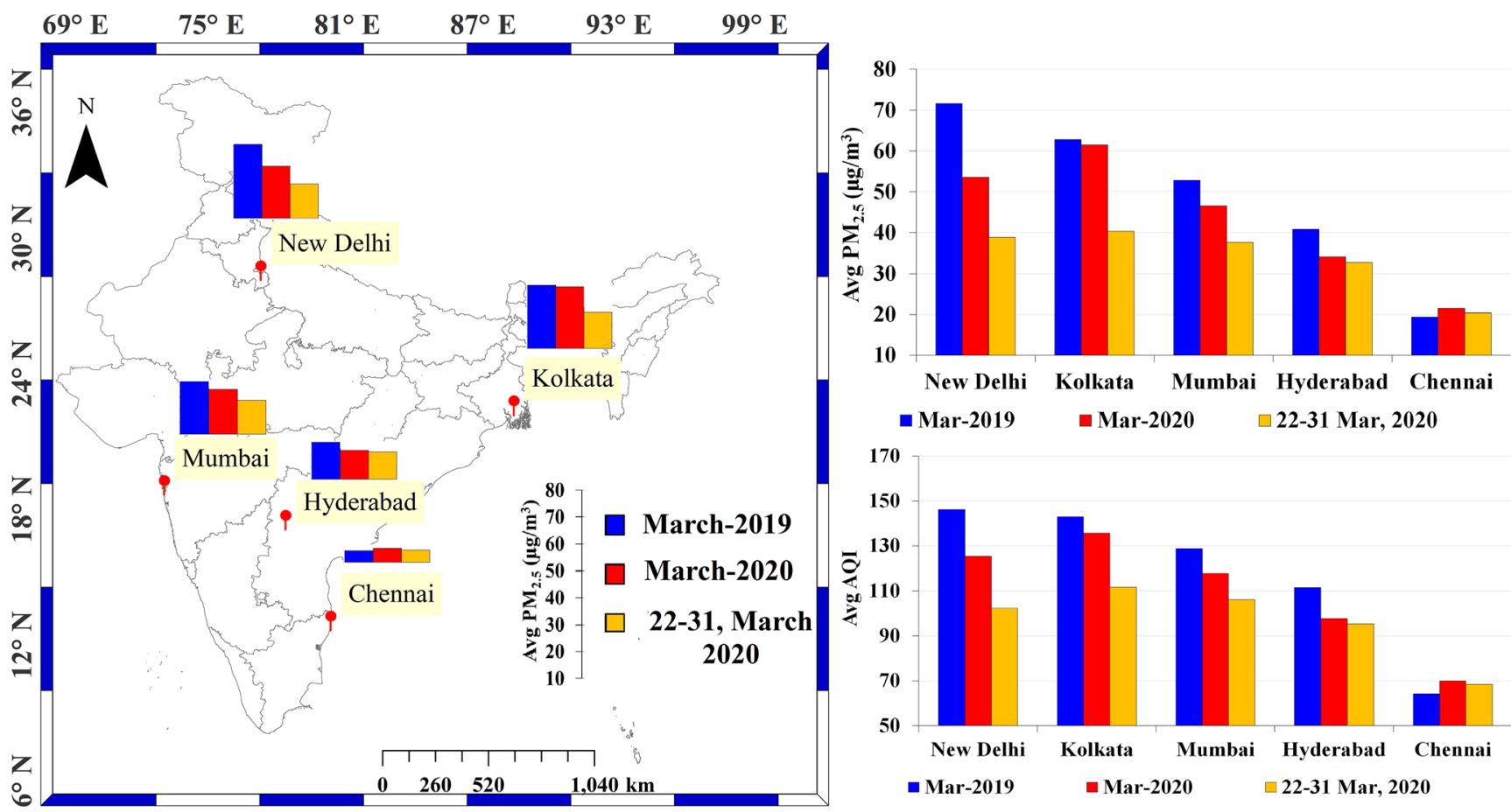

Fig. 1 Left panel shows locations of five US Embassy (Delhi, Kolkata, Mumbai, Hyderabad, and Chennai) along with variations of average $\mathrm{PM}_{2.5}$ during March 2019 (blue bar), March 2020 (red bar), and average during 22-31 March 2020. The lower right panel shows the average AQI over New Delhi, Kolkata, Mumbai, Hyderabad, and Chennai for different periods. In general, $\mathrm{PM}_{2.5}$ and $\mathrm{AQI}$ are reduced during lockdown (22-31 March 2020) compared with March 2019 and March 2020, except in Chennai 
northwestern air mass during March 2019 and March 2020. Over Mumbai, the air mass is reaching from Northern India and also from the Arabian Peninsula during 2019, whereas in March 2020, first half, air mass is coming from the Arabian sea and surrounding regions, and during 22-31 March 2020, air mass is coming from Gujarat, Rajasthan and also from the Arabian Peninsula. In Hyderabad, during 2019 and 2020, the sources of air mass are different; during 2019, air mass is coming from the southern coastal region and western parts of India. But during 2020, air mass is coming from the Bay of Bengal before lockdown, and during lockdown, the air mass is coming from the Indo-Gangetic Plains and the Bay of Bengal (Fig. 2). Over Chennai, the air mass is reaching from the Bay of Bengal in the month of March 2019 and 2020, and during 22-31 March 2020, air mass is coming from the eastern parts of India and from the northern parts (IGP). Kolkata city is located in the eastern part of the Indo-Gangetic Plains and is mostly influenced by westerly air mass except 10-21 March 2019; in this period, air mass is coming from Hyderabad and the Odisha region. The HYSPLIT analysis clearly shows the influence of long-range transport of air mass over five different locations. The westerly air mass brings dust that affect the air quality $\left(\mathrm{PM}_{2.5}\right.$ and AQI) of Delhi, and further, the dust is transported in the eastern parts of the Indo-

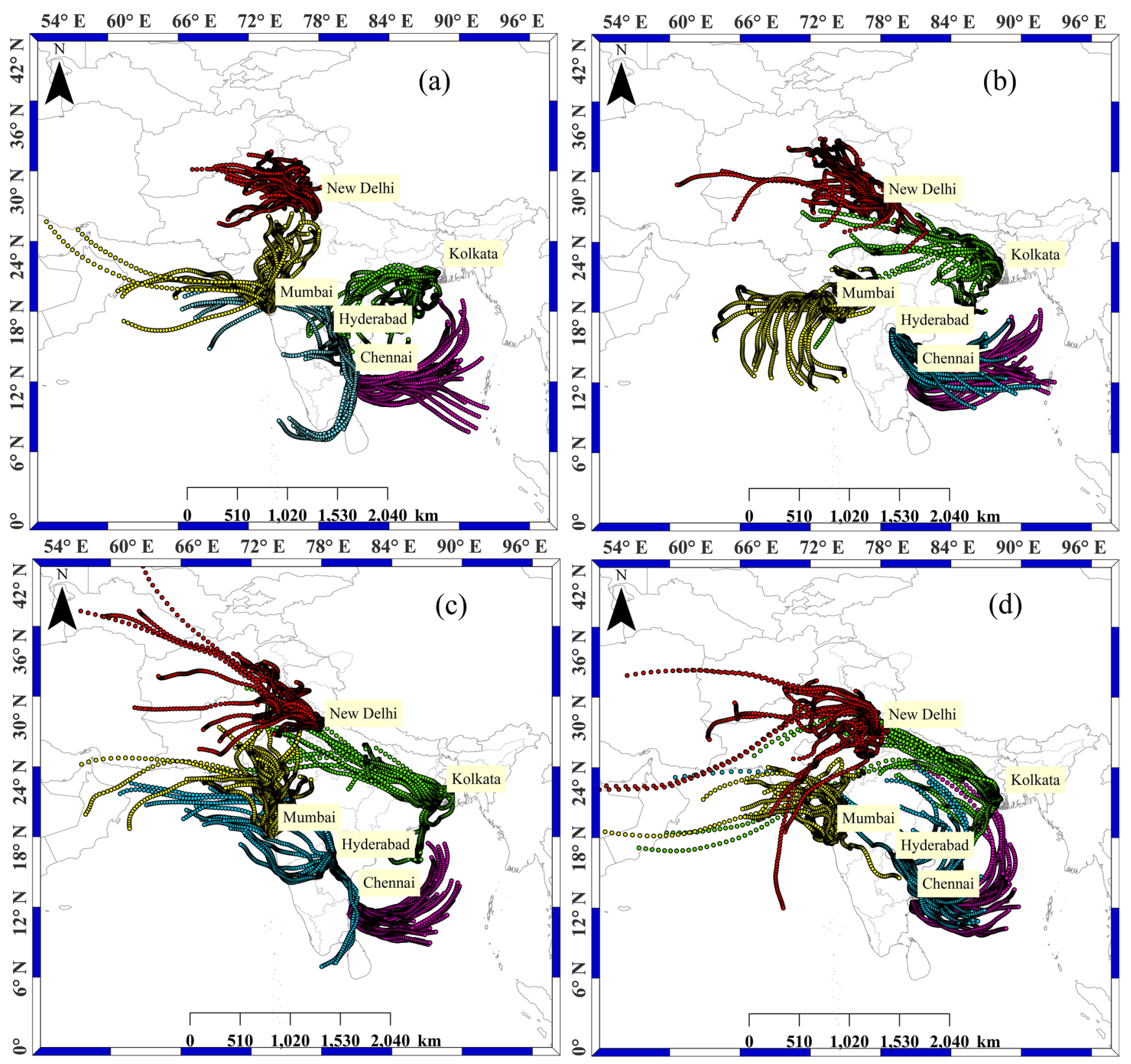

Fig. 2 HYSPLIT back trajectory over Delhi, Mumbai, Kolkata, Hyderabad, and Chennai during (a) 10-21 March 2019, (b) 10-21 March 2020, (c) 2231 March 2019, and (d) 22-31 March 2020 

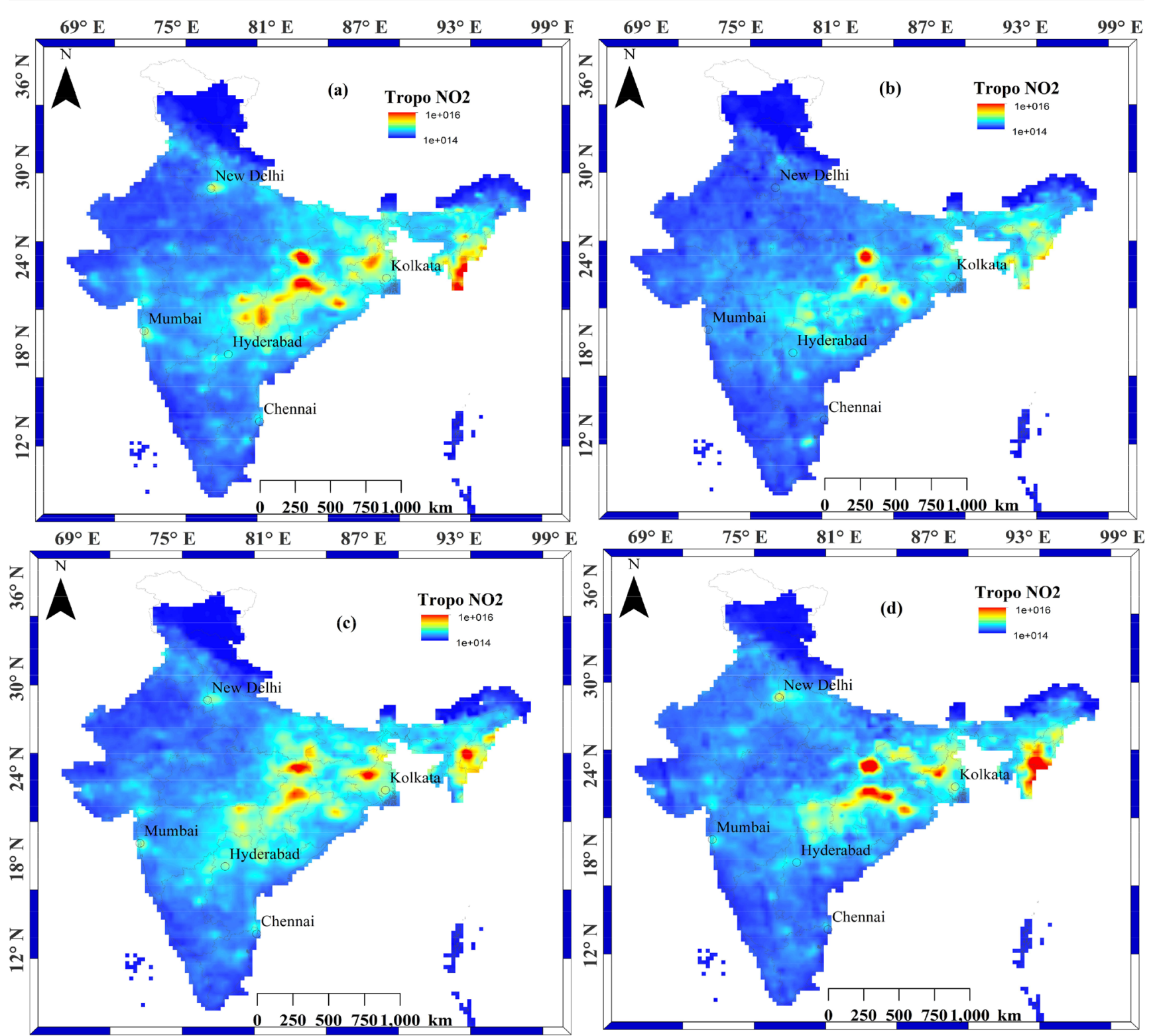

Fig. 3 Spatial variations of tropospheric $\mathrm{NO}_{2}$ over India during (a) 10-21 March 2019, (b) 10-21 March 2020, (c) 22-31 March 2019, and (d) 2231 March 2020. The red circles show the National Capital Region of

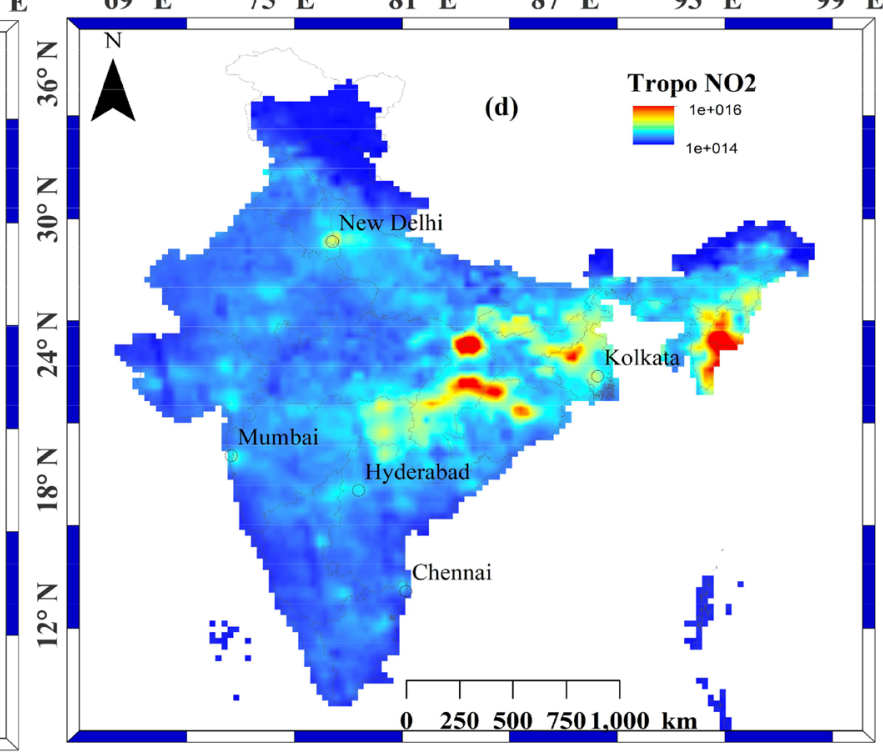

India. Due to lockdown, major sources of anthropogenic emissions were closed; as a result, decline in the tropospheric $\mathrm{NO}_{2}$ concentrations was observed over India

Gangetic Plains affecting air quality of Kolkata city. Although this does not happen always, the transport of dust at Kolkata city depends on the wind velocity; during 10-21 March 2020, the westerly air mass from IGP and long-range transport of air mass from southern India influence this city. At Hyderabad, the sources were different during 2019 and 2020. In Mumbai, mostly the air mass was northerly and westerly except $10-21$ March when dominant air mass comes from the seaside. Chennai is mostly influenced by oceanic air mass. In Chennai, due to change in source of air mass, the average $\mathrm{PM}_{2.5}$ was lower during March 2019 compared with March 2020 and also during the lockdown period (as of 22
March 2020). The long-range transport of the air pollutants influences $\mathrm{PM}_{2.5}$ concentrations in Chennai during 2020; thus, a high value of $\mathrm{PM}_{2.5}$ was observed during March 2020.

In Fig. 3, we have shown tropospheric $\mathrm{NO}_{2}$ over India during March 2019 and 2020 for the periods 10-21 and 2231 March. Over Delhi, Mumbai, and Kolkata cities, the main sources of the $\mathrm{NO}_{2}$ emissions are anthropogenic during the month of March. Generally, in this month, biomass burning influences the southern parts of India; as a result, high $\mathrm{NO}_{2}$ concentration over Chennai and Hyderabad are observed (Sarkar et al. 2018); the fossil fuel consumption also adds to the pollution level. In central Indian states, Jharkhand and 


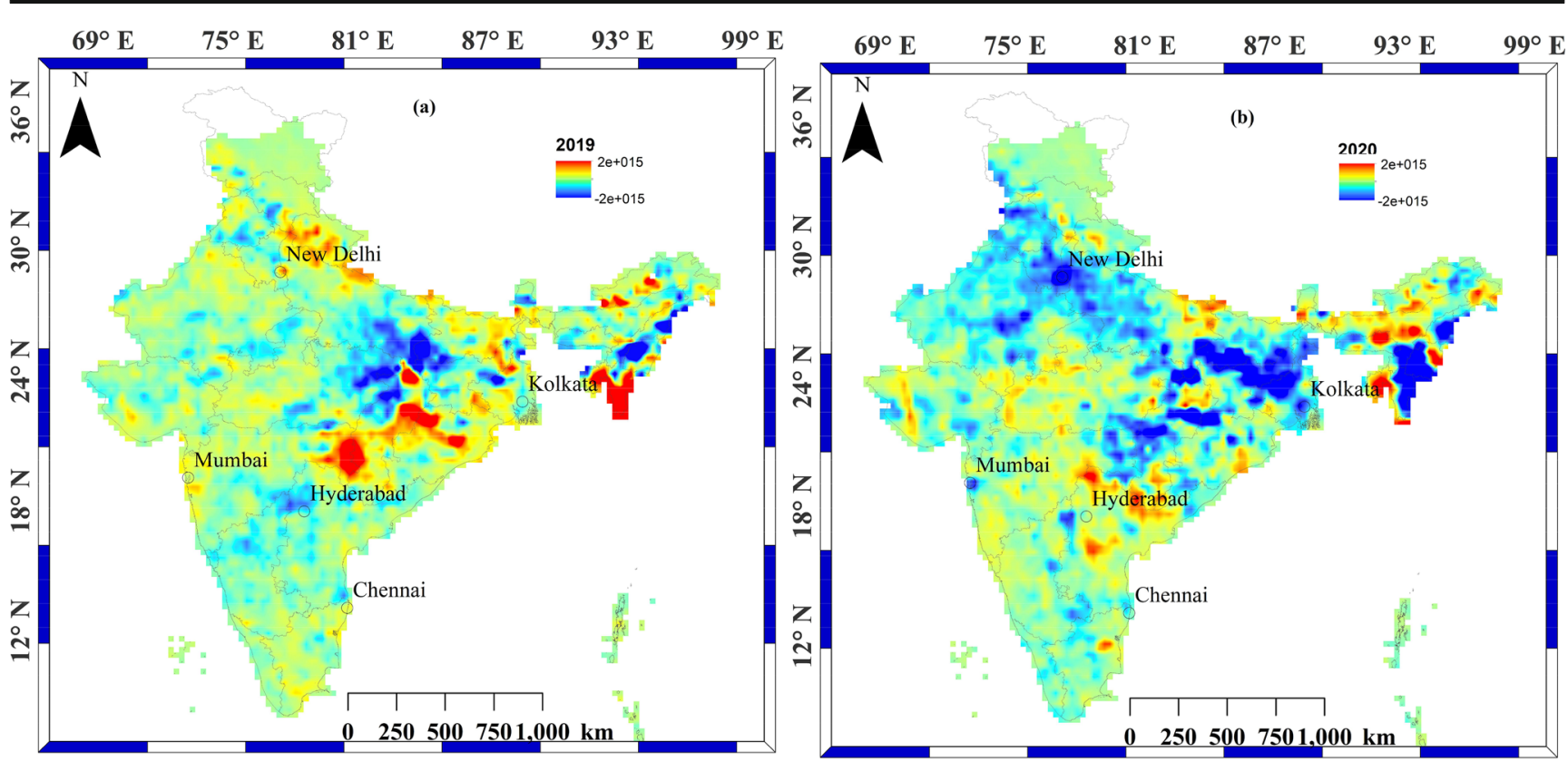

Fig. 4 Difference in Spatial variations of tropospheric $\mathrm{NO}_{2}$ over India for before and after concentration during (a) 2019 and (b) 2020

Odisha, coal-based power plant emissions (Prasad et al. 2006) are the major sources of tropospheric $\mathrm{NO}_{2}$. During March 2019, the average concentration of tropospheric $\mathrm{NO}_{2}$ is observed to be high during 22-31 March 2019; with respect to 10-21 March 2019, an overall high value was observed in most parts in India during 2019. In contrast, during 22-31
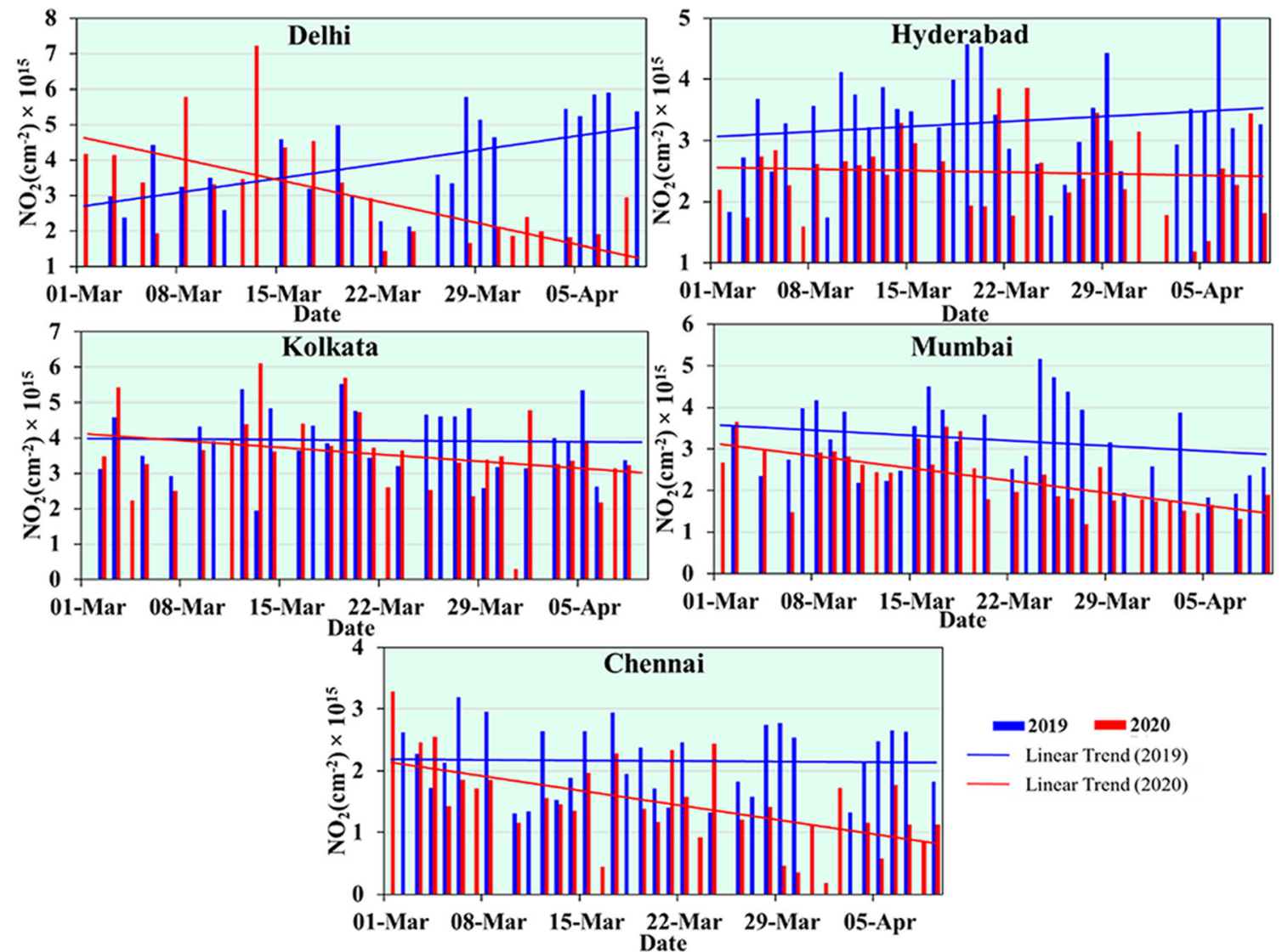

$2019=2020$

- Linear Trend (2019)

Linear Trend (2020)

Fig. 5 Temporal variations of tropospheric $\mathrm{NO}_{2}$ over US Consulate locations (Delhi, Mumbai, Chennai, Hyderabad, and Kolkata) in India during 1 March to 9 April 2020. The blue and red lines show a linear trend in average concentration of tropospheric $\mathrm{NO}_{2}$ during 2019 and 2020. Decreasing trend is seen in all cities, and in Delhi and Kolkata, contrast in trend is seen during 2019 and 2020 
March 2020, the effect of lockdown is clearly observed in the average tropospheric $\mathrm{NO}_{2}$ concentrations in most parts of India. In Figs. 3 a, b, and c, the National Capital Region (NCR, Delhi areas) is the hotspot for $\mathrm{NO}_{2}$ concentrations (high values) in the northern parts, but during the lockdown period in the month of March 2020 (complete lockdown and closure of power plants, factories, vehicles, etc.), the $\mathrm{NO}_{2}$ hotspot is not seen (Fig. 3d). In the month of March 2019, major $\mathrm{NO}_{2}$ hotspots (high values) are observed in Jharkhand, Odisha, and Eastern states. Higher values of tropospheric $\mathrm{NO}_{2}$ concentration is attributed to the dense coal-based power plants and forest fires in Jharkhand and Odisha, and in the Eastern states (Prasad et al. 2006). In the Eastern states, crops' residue is burnt to prepare farms for new crops every year during March (Chauhan and Singh, 2017, Sarkar et al. 2018, 2019). But we also observed a decline in $\mathrm{NO}_{2}$ concentrations during the lockdown period in these parts of India. During the lockdown period starting from 22 March 2020, a sudden drop in tropospheric $\mathrm{NO}_{2}$ concentrations over IGP is observed during 22-31 March 2020 (Fig. 4). Such results clearly show that tropospheric $\mathrm{NO}_{2}$ concentrations are directly related to decline in fossil fuel use and other anthropogenic activities due to complete lockdown in India.

Further, we have carried out a detailed analysis of $\mathrm{NO}_{2}$ concentration and plotted the temporal variations of tropospheric $\mathrm{NO}_{2}$ over five major cities (Fig. 5) for the month of March 2019 (blue bar) and 2020 (red bar). In Delhi, an increasing trend of tropospheric $\mathrm{NO}_{2}$ is seen in 2019, whereas during 2020, a decline in tropospheric $\mathrm{NO}_{2}$ is observed. Soon after the total lockdown after 22 March, a sharp decline in $\mathrm{NO}_{2}$ concentration is observed. In Kolkata, tropospheric $\mathrm{NO}_{2}$ concentration was almost the same (blue trend line) as in the month of March 2019, but in the month of March 2020 (red trend line), a decline in concentration was observed. In Mumbai, in both years, 2019 and 2020, a decline in $\mathrm{NO}_{2}$ tropospheric concentration during 1 March to 9 April was observed, but due to lockdown, low tropospheric $\mathrm{NO}_{2}$ concentration was observed in the year 2020 compared with 2019. In Hyderabad, tropospheric $\mathrm{NO}_{2}$ concentration was also affected by lockdown; in March 2019, high values were observed compared with March 2020; a negative slope (red color line) in the month of March 2020 shows a decline in tropospheric $\mathrm{NO}_{2}$ concentration due to lockdown. In general, in the month of 2020, concentration of tropospheric $\mathrm{NO}_{2}$ was lower during 2020 compared with March 2019. Chennai also shows a decline in tropospheric $\mathrm{NO}_{2}$ values during March 2020. Our results show lower values in tropospheric $\mathrm{NO}_{2}$ due to the lockdown over five US embassies located in major cities in India. In Delhi, Kolkata, and Chennai, a big contrast was observed during the lockdown periods compared with the same periods in 2019, whereas in Mumbai and Hyderabad, decline was not appreciable.

\section{Conclusion}

The lockdown appears to show pronounced improvement in air quality over these large densely populated metropolitan footprints of India where US embassies are located, but the lives of hundreds of millions of Indian people have been disrupted due to the lockdown in response to the COVID-19 pandemic. Our results show a pronounced decline in air pollutants during lockdown especially in Delhi and Kolkata; these two cities are known to be highly polluted cities in India and in the world. The results will attract the attention of the Indian Government to ponder on how to strictly minimize vehicular and industrial pollution to improve air quality which will help to sustain better public health in India.

Acknowledgments The authors are grateful to Environmental Protection Agency (EPA) for providing $\mathrm{PM}_{2.5}$ and AQI data for five US Embassy in India. The authors also thank NASA Giovanni team for facilitating use of tropospheric $\mathrm{NO}_{2}$ satellite data. We are grateful to the two anonymous referees for their useful comments and suggestions that have helped us to improve earlier version of the manuscript.

Author contributions RPS and AC created the original study plan. RPS and $\mathrm{AC}$ designed and executed the study, AC carried out the analysis. RPS and AC wrote the original manuscript and both edited the final manuscripts. Both the authors read and approved the manuscript.

Data availability statement All the data used in the present study are freely available; if needed, we will provide the data used in the present study to anyone.

\section{References}

Chandra BP, Sinha V, Hakkim H, Kumar A, Pawar H, Mishra AK, Sharma G, Garg S, Ghude SD, Chute DM, Pithani P (2018) Oddeven traffic rule implementation during winter 2016 in Delhi did not reduce traffic emissions of VOCs, carbon dioxide, methane and carbon monoxide. Curr Sci 00113891:114(6)

Chauhan A, Singh RP (2017) Poor air quality and dense haze/smog during 2016 in the Indo-Gangetic plains associated with the crop residue burning and Diwali festival. In2017 IEEE International Geoscience and Remote Sensing Symposium (IGARSS), 60486051.

Chauhan A, Singh RP (2020) Decline in PM2. 5 concentrations over major cities around the world associated with COVID-19. Environmental Research 109634.

Krotkov NA, Lamsal LN, Marchenko SV, Celarier EA, Bucsela EJ, Swartz WH, Joiner J, OMI Core team (2019) OMI/Aura $\mathrm{NO}_{2}$ Cloud-Screened Total and Tropospheric Column L3 Global Gridded $0.25^{\circ} \times 0.25^{\circ} \mathrm{V} 3$, NASA Goddard Space Flight Center, Goddard Earth Sciences Data and Information Services Center (GES DISC), Accessed:29/04/2020,https://doi.org/10.5067/Aura/ OMI/DATA3007.

Muhammad S, Long X, Salman M (2020) COVID-19 pandemic and environmental pollution: a blessing in disguise? Sci Total Environ 138820

Prasad AK, Singh RP, Kafatos M (2006) Influence of coal based thermal power plants on aerosol optical properties in the Indo-Gangetic basin. Geophys Res Lett 33 (5). 
Raibhandari B, Phuyal N, Shrestha B, Thapa M (2020) Air medical evacuation of Nepalese citizen during epidemic of COVID-19 from Wuhan to Nepal. J Nepal Med Assoc 58(222). https://doi.org/10. 31729/jnma.4857

Sarkar S, Singh RP, Chauhan A (2018) Crop residue burning in Northern India: increasing threat to Greater India. J Geophys Res-Atmos 123(13):6920-6934

Sarkar S, Chauhan A, Kumar R, Singh RP (2019) Impact of deadly dust storms (May 2018) on air quality, meteorological, and atmospheric parameters over the northern parts of India. GeoHealth 3(3):67-80

Sharma S, Zhang M, Anshika GJ, Zhang H, Kota SH (2020) Effect of restricted emissions during COVID-19 on air quality in India. Sci Total Environ 728:138878

Singh RP, Dey S, Tripathi SN, Tare V, Holben B (2004) Variability of aerosol parameters over Kanpur, northern India. J Geophys ResAtmos 109(D23)

Stein AF, Draxler RR, Rolph GD, Stunder BJ, Cohen MD, Ngan F, Stein AF, Draxler RR, Rolph GD, Stunder BJ, Cohen MD (2015)
NOAA's HYSPLIT atmospheric transport and dispersion modeling system. B Am Meteorol Soc 96:2059-2077

Venkataraman C, Brauer M, Tibrewal K, Sadavarte P, Ma Q, Cohen A, Chaliyakunnel S, Frostad J, Klimont Z, Martin RV, Millet DB (2018) Source influence on emission pathways and ambient $\mathrm{PM}_{2.5}$ pollution over India (2015-2050). Atmos Chem Phys Discuss 8: 8017-8039

Wang P, Chen K, Zhu S, Wang P, Zhang H (2020a) Severe air pollution events not avoided by reduced anthropogenic activities during COVID-19 outbreak. Resour Conserv Recycl 158:104814

Wang C, Horby PW, Hayden FG, Gao GF (2020b) A novel coronavirus outbreak of global health concern. Lancet 395(10223):470-473

Zheng S, Singh RP, Wu Y, Wu C (2017) A comparison of trace gases and particulate matter over Beijing (China) and Delhi (India), Water. Air and Soil Pollution 228(5):181

Publisher's note Springer Nature remains neutral with regard to jurisdictional claims in published maps and institutional affiliations. 